\title{
Redes de cooperación empresarial: Relaciones e interacciones para promover desarrollo turístico local
}

\author{
Narváez, Mercy* \\ Fernández, Gladys**
}

\section{Resumen}

Los modernos modelos de desarrollo plantean como premisa que para alcanzar el progreso de las localidades se debe asegurar mejores condiciones de vida para la población, centrándose en el aprovechamiento de los recursos, la reorganización de los procesos productivos, la creación de nuevas empresas y empleos según los requerimientos del entorno. En este contexto, el presente artículo tiene por objetivo analizar las implicaciones que las redes de cooperación empresarial tienen sobre el desarrollo de las localidades que sustentan sus procesos productivos en la actividad turística. Para ello, se realizó una investigación de tipo documental sustentada en diversas teorías de desarrollo económico local y desarrollo del turismo. Los resultados del trabajo indican que la conformación de redes se sustenta en algunos valores que componen la dimensión relacional denominada "capital social". Además, entre las implicaciones derivadas de la conformación de estructuras empresariales de carácter turístico destacan: aprendizaje colectivo e intercambio, especialización en la prestación de servicios, desarrollo de productos/servicios, creación y desarrollo de nuevas empresas, fortalecimiento de sectores conexos, incremento del nivel de vida de la comunidad y satisfacción de necesidades y expectativas para los visitantes.

Palabras clave: Redes de cooperación empresarial, desarrollo económico local, actividad turística, capital social, sistemas productivos.

Recibido: 15-07-12. Aceptado: 23-01-13

* Licenciada en Administración. Magíster en Gerencia de Empresas. Doctora en Ciencias Gerenciales. Post-Doctora en Ciencias Gerenciales. Profesora Titular e Investigadora de LUZ. Núcleo Punto Fijo, e-mail: romenarvaez@cantv.net; mercynarvaez@gmail.com

** Licenciada en Contaduría Pública. Magíster en Gerencia de Empresas. Doctora en Planificación y Gestión del Desarrollo Regional. Profesora Titular e Investigadora de LUZ Núcleo Punto Fijo. 


\title{
Entrepreneurial Cooperation Networks: Relations and Interactions for Promoting Local Tourism Development
}

\begin{abstract}
Modern development models propose, as a premise, that to achieve progress in localities, better living conditions must be assured for the population, centered on taking advantage of resources, reorganizing productive processes and creating new businesses and jobs, according to the environmental requirements. The objective of this article is to analyze the implications that entrepreneurial cooperation networks have on developing localities that sustain their productive processes for tourism. Documentary research was carried out supported by diverse theories for the development of local economy and tourism. Results indicate that putting networks together is supported by some values that make up the relational dimension called "social capital." Additionally, among the implications derived from creating entrepreneurial structures of a touristic nature, the following stand out: collective learning and exchange, specialization in rendering services, the development of products/services, the creation and development of new businesses, the strengthening of related sectors, an increase in the standard of living for the community and the satisfaction of needs and expectations for visitors.
\end{abstract}

Keywords: Entrepreneurial cooperation networks, local economic development, tourist activity, social capital, productive systems.

\section{Introducción}

El desarrollo económico local depende de la capacidad de integrar el aprovechamiento sostenible de los recursos disponibles y potenciales, movilizándolos hacia la satisfacción de las necesidades y los problemas básicos de la población de una región o territorio. Los aspectos clave de la potencialidad de los recursos para el desarrollo económico de una localidad son: la estructura productiva, el mercado de trabajo, la capacidad empresarial y tecnológica existente, los recursos naturales o ambientales, la estructura social y política, el patrimonio histórico y la cultura local (Alburquerque, 1997:313).

En relación a los elementos que conforman la estructura productiva local, vale decir "las empresas", es necesario que las mismas se organicen en un tejido complejo de relaciones que permita la configuración de redes formales e informales que integren lo sectorial y lo local como aspectos básicos para hacer frente a la competencia global de manera conjunta. Tales redes empresariales integradas a un territorio en particular servirán de base para estimular la conformación de sistemas productivos que promuevan la formación de entornos competitivos e innovadores.

Ahora bien, si se planifica el desarrollo haciendo uso de los recursos y atractivos naturales, patrimoniales o culturales para promover mejores condiciones de vida de alguna población en particular se está haciendo referencia al desarrollo turístico, el cual puede constituirse 
en una opción para enfrentar los desafíos de las regiones o localidades que presentan problemas estructurales o cuyos sectores productivos se encuentran amenazados por los efectos de la competencia global.

Para alcanzar tal desarrollo local soportado en la actividad turística se requiere, entre otros aspectos, la conformación de micro, pequeñas, medianas y grandes empresas, además de emprendedores locales, que sean capaces de ofrecer bienes y servicios que atraigan y retengan los flujos turísticos, por la calidad de los productos y servicios que ofrecen para satisfacer sus requerimientos y necesidades.

Adicionalmente, es necesario comprender que para lograr alcanzar el posicionamiento de las regiones como enclaves turísticos se hace necesaria la conformación de sistemas o redes productivas empresariales constituidas por las organizaciones turísticas que estén ubicadas en el mismo espacio geográfico y que sean capaces de conjugar esfuerzos y experiencias para hacer frente a destinos turísticos más competitivos y consolidados.

Sobre este particular, Iglesias y Ramírez (2008:55) exponen que la sola concentración territorial de empresas no conlleva automáticamente a la existencia de un sistema productivo; es necesario que entre las organizaciones medie un sistema de relaciones, de preferencias que induzca a los miembros de estas a preferir integrarse con otros.

A la luz de estos planteamientos se presenta este artículo, el cual tiene por objetivo analizar las implicaciones que las redes de cooperación empresarial tienen sobre el desarrollo de las localidades que sustentan sus procesos productivos en la actividad turística.

En lo relacionado a la metodología empleada, la misma se corresponde con un diseño de tipo documental respaldado en la construcción de un marco teórico de referencia, basado en el análisis del texto escrito, derivado de la evaluación de contenidos relacionados a las vigentes teorías de redes empresariales, desarrollo local y desarrollo del turismo como actividad económica generadora de riqueza y potenciadora de procesos de promoción local. De igual manera, se recurrió al mapeo teórico conceptual, herramienta de gran ayuda a la hora de representar gráficamente las líneas que soportan las relaciones e implicaciones que se derivan del análisis realizado.

\section{Aspectos conceptuales de las redes de cooperación empresarial}

Los actuales escenarios en los cuales se desenvuelven las empresas originan la necesidad de que las mismas adopten estrategias empresariales que les permitan dar respuestas a los desafíos y a las demandas de entonos dinámicos, cambiantes y complejos. Es por ello, que las redes empresariales sustentadas en la cooperación se han convertido en un medio que utilizan las empresas para hacer frente a los mercados y alcanzar ventajas competitivas de manera conjunta.

En correspondencia con lo antes descrito González (2003:2) señala que la posición competitiva de una empresa no depende solo de su capacidad interna, sino también del tipo de relaciones que sea capaz de establecer con otras em- 
Redes de cooperación empresarial: Relaciones e interacciones para promover... Narváez, Mercy y Fernández, Gladys

presas y del alcance de dichas relaciones. Para la autora citada dentro de las diferentes formas estratégicas de relación empresarial destacan las alianzas, coaliciones, acuerdos de cooperación o de colaboración y redes.

Ahora bien, para efectos de este artículo se hará especial énfasis al concepto de redes empresariales, las cuales son contempladas como organizaciones de empresas independientes, entre las que no existe una relación de subordinación, que mantengan vínculos cooperativos, por medio de los cuales sean capaces de realizar acciones conjuntas coordinadas (González, 2003:4).

Por su parte, Fernández y Arranz (1999:14) consideran que las redes consisten en una forma de cooperación entre organizaciones en la que, mediante el establecimiento de unos lazos relacionales -relaciones administrativas- éstas se implican en la realización de un proyecto empresarial. Las mismas se caracterizan por la existencia de una pluralidad de acuerdos entre diversos participantes, bien sean empresas o entre éstas y otro tipo de instituciones públicas y privadas.

Los autores citados también señalan que los nodos de la red se conforman con las organizaciones o empresas participantes, siendo los acuerdos de cooperación los eslabones o lazos que los unen en la red, adicionalmente los elementos clave que la definen son la multiplicidad y la complejidad de relaciones.

Para Bonomie y Meleán (2007:9), la red como forma de organización, permite a las empresas interrelacionadas diseñar estructuras, aprovechar sinergias, adquirir poder de negociación frente a los compradores de sus productos, aprovechar economías de escala, crear barreras de entrada que le permitan obtener una posición de dominio en el mercado, entre otros. Para ello, las empresas se valen de estrategias de asociación, colaboración o cooperación, donde se requiere la coordinación y sincronización de cada una de las actividades productivas, de los tiempos y esfuerzos como aspectos esenciales para lograr la complementariedad entre empresas y ofrecer productos competitivos en el mercado (liderazgo en costos, calidad, diferenciación, entre otros).

En síntesis, para efectos de este trabajo las redes se pueden definir como sistemas complejos de empresas vinculadas entre sí, compuestos por relaciones de intercambio e interdependencia entre los componentes de la misma, en consecuencia las interacciones producidas en la red se deben interpretar desde el punto de vista de la colaboración y la cooperación con el propósito de dar respuesta a las demandas que se imponen a las empresas en el contexto global.

Ahora bien, las redes de cooperación empresarial se constituyen con la expectativa de alcanzar determinados objetivos, al respecto Francés (2008:266) plantea los siguientes:

- De eficiencia: persiguen mejorar el desempeño sin modificar las capacidades o los activos disponibles (economías de escala y ámbito, sistemas de apoyo conjunto, utilización de capacidad, riesgo compartido, combinar o intercambiar productos, costos de transporte).

- Mejorar capacidades: este objetivo se refiere al proceso de desarrollar com- 
petencias e incrementar los conocimientos empresariales (capacidades complementarias, uso de destrezas, aprendizaje por interacción, externalidades de ubicación, flexibilidad de configuración).

- Posicionamiento: se refieren a la relación con el entorno (consideraciones políticas, satisfacer exigencias de gobiernos locales, acceso a mercados, acceso rápido a nuevos mercados de productos e insumos, ajuste de productos, tecnología o insumos a las condiciones del mercado local, seguir al cliente, establecer estándares en el mercado, competencia, bloquear el acceso de un competidor a recursos, bloquear entrada o salida de competidores).

Ahora bien, en correspondencia con lo hasta aquí descrito y según señala Vega (2004:44-45) los objetivos y la naturaleza de las redes empresariales deben responder a ciertas demandas del entorno, tales como: necesidad del crecimiento económico sostenible (en términos de la búsqueda de la cohesión social y del bienestar), necesidad de las empresas de complementarse entre sí, mayor posibilidad para acceder al conocimiento, necesidad de insertarse en el nuevo modelo competitivo, articulación de intereses, pertenencia a un sistema dinámico e interactivo, principalmente.

Es decir, las redes de cooperación empresarial permiten aumentar la competitividad de las empresas cooperadoras ante terceros, considerando a los competidores como posibles aliados y como fuente de información, lo cual promueve un ambiente de mercado concertado (González, 2007:14).

\section{El desarrollo local y las redes de cooperación empresarial}

Artesi (2002:76) señala que la teoría de las redes es una aplicación de la teoría de los sistemas y a partir de esta perspectiva se pueden entender los factores que estimulan la generación de dinámicas locales en el marco de sistemas productivos localizados y la emergencia de formas de acción colectiva. Desde este punto de vista se hace necesario aprovechar el énfasis que la economía global coloca en el rol del territorio y de los sistemas productivos locales ya que en la actualidad se desarrolla un proceso de apertura internacional de las redes productivas con una extraordinaria capacidad de penetración en los mercados y una dinámica de las exportaciones que parece privilegiar las áreas de los nuevos competidores.

En tal sentido, se puede decir que en el marco del escenario global las empresas tienen mayores probabilidades de alcanzar niveles de excelencia si el contexto en el que están localizadas contribuye a mejorar su especialización y valoriza su especificidad. Asimismo, el concepto de sistema basado en redes reconoce un nuevo rol a las economías que se expanden desde los entornos locales. Esta dialéctica empresa-territorio alude a los modelos del desarrollo vinculados a la articulación entre proximidad geográfica y proximidad organizacional que promueven la expansión de una dinámica compleja de interacciones entre empresas y territorio.

En el marco del contexto antes descrito, se hace mención al modelo de desarrollo local, el cual es un enfoque terri- 
Redes de cooperación empresarial: Relaciones e interacciones para promover... Narváez, Mercy y Fernández, Gladys

torial y de "abajo-arriba" que busca intervenciones de niveles decisionales del Estado (provincia, región y nivel central) que faciliten el logro de los objetivos de la estrategia de desarrollo. Para alcanzarlo se requiere de una eficiente coordinación de los diferentes niveles territoriales de las administraciones públicas y de un contexto integrado de las diferentes políticas de desarrollo entre esos niveles. Igualmente, se destaca que este es un enfoque unificado que se sustenta tanto en aspectos ambientales como culturales, sociales, institucionales y de desarrollo humano en el ámbito territorial (Alburquerque, 2003:8).

En relación a la estructuración productiva, el enfoque del desarrollo local plantea el cambio estructural de formas de producción "fordistas" a formas de producción basadas en la incorporación de conocimientos sobre la segmentación de mercados, calidad y diferenciación de la oferta productiva, y mejora de las redes territoriales de apoyo a la producción y de cooperación de actores públicos y privados locales. En este enfoque, se insiste en que las empresas no compiten de manera aislada, sino a través del conjunto de eslabonamientos de las cadenas productivas.

En concordancia con lo planteado, Vázquez (2000:24) señala que la configuración del modelo de producción mediante una red de empresas denominada "sistemas productivos locales" se constituye en la columna vertebral del desarrollo económico local. Dicha red está formada por actores locales, recursos (humanos, naturales, infraestructuras), actividades económicas (de carácter productivo, comercial, técnico, financiero, asistencial) y sus relaciones (interdependencia e intercambios); estas relaciones dentro de la red permiten que los actores intercambien no sólo productos y servicios sino también conocimientos tecnológicos $y$ pautas de comportamiento.

En consecuencia, se puede acotar que los sistemas productivos locales se componen de redes internas en las que se dan relaciones de cooperación y competencia entre organizaciones empresariales. La cooperación en el sistema productivo local se basa en el beneficio que proporciona a cada una de las empresas la combinación de esfuerzos para obtener economías de escala, reducir costos de transacción, generar procesos de aprendizaje colectivo, acceder a mercados más exigentes y avanzados, y además algo muy importante, constituirse en palanca potenciadora para la generación de procesos de desarrollo económico local.

De manera simplificada se puede decir que los sistemas productivos locales surgen en ámbitos territoriales específicos, se configuran mediante redes empresariales y se sustentan en la cultura social y productiva de una región o localidad, siendo según lo planteado por Iglesias y Ramírez (2008:60) sus características distintivas las siguientes:

- Concentración de un conjunto de empresas (principalmente pequeñas y medianas "rivales entre si") en espacios territoriales restringidos que se especializan en la fabricación de un producto o en la prestación de servicios.

- Como resultado de las relaciones y conexiones de estas empresas se generan procesos de expansión basados en economías externas a las empre- 
sas, pero internas al sistema productivo local.

- Se apoyan en la experiencia y la calificación profesional; una intensa división del trabajo entre firmas con densas redes de relaciones materiales e intangibles (difusión de ideas e información e innovación sobre procesos y productos) y la especialización en alguna rama o sector.

- Coexistencia de relaciones de cooperación formales e informales en las fases de comercialización, fabricación o Investigación y Desarrollo (I\&D); y la existencia de un mercado de trabajo flexible pero con tradición laboral.

- La constante interacción e intercambio entre empresas fomenta la difusión de innovaciones, procesos colectivos de aprendizaje, aumento de la productividad y competitividad, reducción de costos, entre otros.

Ahora bien, cabe destacar que los procesos de desarrollo local se originan en el contexto del territorio, puesto que éste se convierte en un actor clave para la conformación de redes constituidas por pequeñas y medianas empresas que se complementan con los diferentes agentes locales y sacan provecho de los bienes, recursos y potencialidades del espacio geográfico (capital humano, capital natural y financiero, capacidad de innovación y estructura productiva), independientemente del tipo que sean. Es por ello, que las redes pueden desarrollarse atendiendo a diferentes actividades productivas (industriales, comerciales o de servicios) y en cualquier localidad obteniendo beneficio de los recursos con que cuenta o dispone el territorio.
En el caso del desarrollo de redes de cooperación empresarial en el sector servicios turísticos Varisco (2007:25) destaca que en las mismas la dimensión territorial siempre está presente dado que los recursos turísticos, naturales y culturales, son inherentes al territorio, y en los destinos consolidados, la imagen turística trasciende el sector y forma parte de la identidad local. La dimensión histórica define la forma en que la actividad se desarrolla a través del tiempo y en los casos en que el turismo es la actividad de base económica, esta historia es inseparable de la localidad o destino independientemente de donde se encuentre ubicado el mismo.

Varisco (2007) señala que la integración empresarial se puede presentar de manera formal e informal. A nivel vertical, la integración formal se produce en los casos en que un operador mayorista enlaza los servicios básicos en un paquete turístico. De manera informal, siempre existe integración vertical en el producto que el turista selecciona, aunque sea de manera independiente. Esto remite a la interdependencia de los servicios turísticos. También los eslabonamientos productivos son una forma de integración que relaciona al sector proveedor de alimentos, las manufacturas y los servicios. Los grupos empresariales que comparten la propiedad de varios establecimientos representan otra forma de integración, que puede ser vertical u horizontal, como en el caso de las cadenas hoteleras. Por último, la integración transversal está presente en el concepto de producto global que caracteriza al destino, y su grado de formalidad dependerá de la definición explícita, como por ejemplo, la que 
Redes de cooperación empresarial: Relaciones e interacciones para promover... Narváez, Mercy y Fernández, Gladys

se produce en el posicionamiento deseado para un destino a partir de un plan estratégico de desarrollo.

\subsection{Tipología de los sistemas productivos locales}

Los sistemas productivos locales se estructuran de diversas formas dependiendo de su forma de organización, el grado de integración de las empresas que los conforman y el lugar donde estén localizadas. En tal sentido, según Vázquez (2005:9-10) se destacan los siguientes tipos:

- Sistemas productivos locales, formados por empresas vinculadas entre sí y cuyas actividades productivas están integradas en la cadena de producción de la ciudad o región donde se localizan.

- Sistemas productivos locales, cuyas empresas realizan actividades que se vinculan a cadenas de producción de otras ciudades o regiones, debido a que algunas de las fases importantes de la cadena de producción se realizan fuera del territorio en el que se localizan las empresas.

- Sistemas productivos locales, formados alrededor de grandes empresas que realizan todas las funciones (o las más importantes) en la localidad en la que se localizan y cuyas actividades están integradas en la cadena de producción local.

- Sistemas productivos locales articulados alrededor de empresas que forman cadenas de producción externas y carecen de vinculaciones productivas locales significativas.

Al respecto de los tipos de sistemas productivos locales expuestos en este aparte se presenta el Cuadro 1, el cual muestra de manera resumida los criterios que se utilizan para estructurar dichos sistemas productivos de carácter local.

En el caso de las redes de cooperación empresarial en el contexto de la actividad turística (sector empresarial sobre el que se hace especial referencia en este trabajo), estas se constituyen en la mayo-

Cuadro 1

Tipología de los Sistemas Productivos Locales

\begin{tabular}{|c|c|}
\hline $\begin{array}{ll} & \text { Tipología } \\
\text { Criterios } & \\
\end{array}$ & Sistemas de Producción Locales \\
\hline $\begin{array}{l}\text { Formas de organización } \\
\text { empresarial }\end{array}$ & $\begin{array}{l}\text { - Empresas vinculadas entre si } \\
\text { - Empresas vinculadas alrededor de grandes empresas } \\
\text { - Empresas vinculadas alrededor de cadenas de producción ex- } \\
\text { ternas a la localidad }\end{array}$ \\
\hline Grado de integración & $\begin{array}{l}\text { Integración con: } \\
\text { - Cadenas de producción local } \\
\text { - Cadenas de producción de otros localidades } \\
\text { - Nula vinculación productiva local }\end{array}$ \\
\hline Localización & Ubicación geográfica (ocupación de un mismo espacio) \\
\hline
\end{tabular}

Fuente: Elaboración propia, adaptado de Vázquez (2005). 
ría de los casos por el conjunto de pequeñas y medianas empresas u organizaciones vinculadas entre sí por el mismo hecho de la prestación de bienes o servicios de carácter turístico, es decir, empresas de alojamiento, restauración, intermediación turística, transporte, servicios complementarios, entre otras; que se encuentran localizadas en la misma región o espacio geográfico.

\section{El turismo: Actividad potenciadora del desarrollo local}

El turismo es definido por Mc.Intosh et al. (2008:26) como la suma de los fenómenos y relaciones que surgen de la interacción de turistas, proveedores de negocios, gobiernos y comunidades anfitrionas en el proceso de atraer y alojar a turistas y visitantes hacia una determinada región o localidad. Desde la perspectiva económica el turismo es la suma total de los gastos que realizan los turistas dentro de los límites de una nación o subdivisión política o área económica.

Al respecto de la previa definición se puede derivar que el turismo genera sobre el contexto territorial un conjunto de efectos o impactos significativos, fundamentalmente de tipo económico, razón por la cual puede ser considerado como factor de desarrollo local.
En correspondencia con tal afirmación Calderón (2010) expresa que el turismo desempeña en algunos países subdesarrollados y en áreas periféricas un rol decisivo en el desarrollo económico, constituyendo una actividad motriz y diversificadora, generadora de empleo y de exportación, muy importante para el fortalecimiento de su estructura económica. Igualmente, a partir de la crisis económica de los 80, la actividad turística en los países desarrollados se ha considerado como revitalizadora, particularmente para áreas en declive, zonas atrasadas y como generadora de empleo.

Así pues, si se analiza el turismo desde el punto de vista de la producción, es evidente que presenta todas las características de una industria capaz de generar producciones impulsoras ${ }^{1}$, ya que no sólo utiliza la materia prima existente en el lugar (recursos turísticos) sino que hace uso en gran medida de la mano de obra local disponible. Además, para poder efectuar el consumo, el turista debe trasladarse hasta el destino donde se localizan los atractivos que le son ofrecidos, el gasto que realiza una vez que se encuentra en el lugar equivale a una verdadera exportación, ya que se está pagando con dinero proveniente del exterior o de cualquier otro punto del país, pero ajeno a la región (Acerenza, 2007:25).

1 Las industrias que generan las producciones impulsoras, son aquellas que cuentan con capacidad de inducir el crecimiento de las industrias relacionadas y que exportan hacia el exterior, u otras regiones del país, bienes y servicios generados en la región en la cual están instaladas, creando con esto flujo de dinero hacia las mismas, proveniente desde el exterior, o desde otros puntos del territorio del propio país, pero siempre desde puntos externos a ella. 
Redes de cooperación empresarial: Relaciones e interacciones para promover... Narváez, Mercy y Fernández, Gladys

Asimismo deben existir algunas condiciones para afirmar que el impacto del turismo es beneficioso para un territorio o región, entre dichas condiciones destacan (Acerenza, 2007):

- Se produce un traslado efectivo de capital desde las zonas económicas más desarrolladas hacia la región, y dicho capital es utilizado en el desarrollo de infraestructura y el equipamiento turístico, es decir, en la construcción de hoteles, en los servicios complementarios y en las empresas relacionadas.

- Se utiliza al máximo la mano de obra local disponible no solo en los servicios turísticos, sino también en toda la industria y en las actividades relacionadas.

- Los insumos requeridos para el desarrollo de la actividad provienen de la propia región y, por lo tanto, el componente importado en el consumo es mínimo.

- Los beneficios de explotación obtenidos por los hoteles, empresas prestadoras de servicios complementarios, así como las industrias y actividades relacionadas son reinvertidos en la propia región.

- Se regulan de manera adecuada los procesos relacionados con el desarrollo urbano y la prestación de servicios públicos básicos requeridos por la comunidad local y sus alrededores.

Sin embargo, se hace necesario referir que desde la perspectiva del desarrollo económico no todos los impactos que se producen por el desarrollo de la actividad turística son beneficiosos para una región o un territorio. Al respecto, se reseñan en el Cuadro 2, los principales efectos tanto favorables como desfavorables del desarrollo de la actividad turística en las localidades.

\subsection{Redes de cooperación de empresas turísticas}

En el ámbito del turismo Morrison et al. (2004:200) definen las redes empresariales como un sistema de relaciones cooperativas formales que se generan entre organizaciones turísticas, cuya intención es estimular el aprendizaje interorganizacional y el intercambio de conocimiento, así como un sentido de comunidad y propósito común colectivo, para dar lugar a ventajas cualitativas y/o cuantitativas de una actividad económica, generando al destino y empresas turísticas una capacidad competitiva única, sostenible para la comunidad anfitriona.

En la misma direccionalidad de la idea precedente, Martín y Gaspar (2008: 46) expresan que dada la naturaleza multisectorial de esta actividad y la necesidad continua de innovación y adaptación rápida a los cambios, la cooperación constituye una forma de crecimiento idónea para estas organizaciones, proponiéndose la creación de redes como una alternativa para crear sinergias y mejorar la competitividad del tejido empresarial turístico, siendo algunos de sus objetivos: compartir Know-how, compartir tecnología, especialización de funciones, obtener financiamiento, obtención de economías de escala, entre otros.

Adicionalmente, Andreu y Parra (2007:400) señalan que una red de empresas turísticas debe estar compuesta por una serie de actividades, y el más mínimo movimiento de cualquiera de los 


\section{Cuadro 2}

\section{Efectos del turismo en el desarrollo económico local}

\begin{tabular}{|c|c|}
\hline Aspectos Positivos & Aspectos Negativos \\
\hline $\begin{array}{l}\text { - Estimula la dinamización del sistema econó- } \\
\text { mico en virtud de las complejas relaciones } \\
\text { que se generan entre los distintos sectores } \\
\text { empresariales y los actores económicos loca- } \\
\text { les vinculados a la actividad turística. } \\
\text { - La actividad turística se constituye en una in- } \\
\text { dustria exportadora que capta divisas: el turis- } \\
\text { ta visita la región y consume productos y ser- } \\
\text { vicios en la localidad; dichas divisas resultan } \\
\text { imprescindibles para fomentar procesos de } \\
\text { desarrollo económico local. }\end{array}$ & $\begin{array}{l}\text { - El turismo requiere crecientes importaciones } \\
\text { para abastecer los productos demandados } \\
\text { por los visitantes (si se da un crecimiento sus- } \\
\text { tancial de importaciones como consecuencia } \\
\text { de la actividad turística se reduce el efecto ex- } \\
\text { pansivo del turismo, lo cual debilita su capaci- } \\
\text { dad para actuar como instrumento de desa- } \\
\text { rrollo). } \\
\text { - Genera una demanda excesiva de recursos y } \\
\text { servicios que en muchas ocasiones afecta la } \\
\text { localidad receptora o anfitriona. }\end{array}$ \\
\hline $\begin{array}{l}\text { - Permite la construcción de infraestructuras tu- } \\
\text { rísticas y recreativas que pueden ser utiliza- } \\
\text { das por la población local. } \\
\text { - Se constituye en fuente de generación de em- } \\
\text { pleo para las comunidades anfitrionas o re- } \\
\text { ceptoras de la actividad turística. }\end{array}$ & $\begin{array}{l}\text { - En muchos casos la inversión en infraestruc- } \\
\text { tura turística es realizada por capital foráneo, } \\
\text { lo cual puede generar un control de la activi- } \\
\text { dad por organizaciones extranjeras, poco } \\
\text { comprometidas con las necesidades del de- } \\
\text { sarrollo territorial. }\end{array}$ \\
\hline $\begin{array}{l}\text { - El capital natural, cultural y patrimonial de la } \\
\text { región o localidad se constituye en el principal } \\
\text { activo que sirve de base para el desarrollo de } \\
\text { la industria turística. }\end{array}$ & $\begin{array}{l}\text { - Las demandas de la actividad turística pue- } \\
\text { den entrar en conflicto con las necesidades y } \\
\text { deseos de los residentes de las localidades } \\
\text { receptoras. }\end{array}$ \\
\hline $\begin{array}{l}\text { - La actividad turística origina la aparición de } \\
\text { micro, pequeñas, medianas y grandes em- } \\
\text { presas, además de emprendedores locales, } \\
\text { lo que estimula la creación de redes empresa- } \\
\text { riales y en consecuencia mayores niveles de } \\
\text { actividad económica. }\end{array}$ & $\begin{array}{l}\text { - Puede provocar un desarrollo económico de- } \\
\text { sequilibrado si no se planifica y gestiona de } \\
\text { manera organizada y consensuada entre to- } \\
\text { dos los actores involucrados. }\end{array}$ \\
\hline
\end{tabular}

Fuente: Elaboración propia (2012).

agentes involucrados en la misma, se puede considerar como una potencial colaboración que puede ayudar a la competitividad de la red.

Entre las actividades que se pueden desarrollar en una red de empresas turísticas destacan: colaboración en el desarrollo y diseño de productos turísticos, gestión y análisis de la demanda, desarrollo y gestión de recursos de colaboración, coproducción de productos turísticos (particularmente paquetes de turismo produc- tos/servicios), comercialización del destino, posicionamiento y marca del destino y gestión de servicios al turista. Incluso, la colaboración puede apoyar el desarrollo de estrategias sostenibles y competitivas para el destino turístico (Andreu y Parra, 2007).

Ahora bien, para efectos de la configuración de una red de cooperación en el ámbito turístico se consideran en este artículo aquellas organizaciones empresariales vinculadas con la prestación de 
Redes de cooperación empresarial: Relaciones e interacciones para promover... Narváez, Mercy y Fernández, Gladys

servicios en dicha actividad. Al respecto Parra y Calero (2006:40) señalan que las empresas turísticas por ser prestadoras de servicios se ubican en el sector terciario, ofreciendo servicios en: alojamiento (hoteles, apartamentos, campamentos, alojamiento rural), restauración (restaurantes, bares, cafeterías), intermediación turística (mayoristas, tour operadoras, agencias de viaje, centrales de reserva), trasporte turístico y auxiliares (transporte aéreo, marítimo, terrestre), oferta complementaria (actividades culturales, deportes y de ocio, parques temáticos, servicios profesionales, casinos).

Se destaca que las relaciones que se plantean para este tipo de red empresarial que se orienta a la promoción del desarrollo turístico local se sustentan en el modelo presentado por Fernández y Narváez (2011:301-302) que señala:

- El acuerdo de cooperación empresarial es horizontal, por tanto las empresas prestadoras de servicios turísticos (restauración, transporte, agencias de viajes, alojamiento, recreación), cooperan en algunas actividades, pero a su vez compiten entre sí en un mismo mercado.

- El carácter del acuerdo es competitivo entre empresas competidoras directas pertenecientes a un mismo sector productivo.

- El alcance geográfico es a nivel local, fundamentado en el desarrollo endógeno. Es importante destacar que la proximidad geográfica es un elemento clave en el establecimiento de redes empresariales horizontales por la presencia de factores tales como el capital social, compartir recursos comu- nes, tradición productiva, entre otros. Esto facilita el intercambio de información y recursos entre las empresas que conforman la asociación.

\subsection{Ventajas de la conformación de redes de empresas turísticas}

Las ventajas del establecimiento de una red de empresas turísticas se resumen según lo expresado por Lynch (2000) en tres categorías importantes: aprendizaje e intercambio, actividades económicas y comunidad.

Por otra parte, Skyrme citado por Andreu y Parra (2007:401) muestran que una red estructurada sobre la base del conocimiento puede beneficiar a las empresas turísticas en: a) una reacción flexible a los requisitos de mercado, es decir, la recolección e intercambio de información proporciona un mayor conocimiento de las tendencias y permite el desarrollo, en tiempo, de productos innovadores para el turismo; b) desarrollo de nuevas capacidades como base de la red: el conocimiento se combina con otros recursos para ser beneficioso al cliente y crear ventajas competitivas; c) combinar recursos y acciones de colaboración, sin renunciar a la independencia de las empresas; d) alcanzar una alta satisfacción de los visitantes: aprender más del turista, sus necesidades y las expectativas, para desarrollar productos apropiados; y e) explotación de sinergias.

De igual forma, Fernández y Narváez (2011:299-300) señalan que las ventajas de conformar redes empresariales en el sector turístico vienen dadas principalmente por razones financieras, 
organizacionales y de mercadeo. En lo referente a las razones financieras por las cuales las organizaciones del sector conforman redes, sed estaca que estas apuntan al acceso a financiamiento para cubrir las garantías entre todos los participantes y la inversión conjunta para la ejecución en común de proyectos turísticos. Desde la perspectiva organizacional, las razones para interrelacionarse están principalmente dirigidas a la capacitación conjunta del recurso humano, mejora de procesos operativos y el intercambio de información productiva o tecnológica. En relación al área de mercadeo, las razones por las cuales cooperan las empresas del sector turístico se enfocan al desarrollo de nuevos servicios, promoción y comercialización del servicio y apertura de nuevos mercados.

En atención a lo expresado en párrafos previos, se presenta en el Cuadro 3 , un resumen de las principales implicaciones derivadas de la conformación de redes empresariales de carácter turístico y los principales actores de las localidades o territorios beneficiados con la configuración de dichas redes.

\subsection{Valores para la conformación de redes empresariales turísticas}

La premisa fundamental para la conformación de una red empresarial vinculada con la actividad turística gira en torno al desarrollo de procesos de cooperación y sinergias entre los actores que la integran para asegurar el logro de objetivos específicos y una visión compartida de la localidad como destino turístico a futuro. Sin embargo, para la consolidación de este tipo de estructuras en el ámbito turístico se requiere de una serie de valores que se sustentan en la dimensión relacional denominada "capital social".

Newton citado por Kliksberg (1999:87) opina que el capital social puede ser asumido como un fenómeno subjetivo, compuesto de valores y actitudes que influyen en la forma en que se relacionan las personas. Incluye confianza, normas de reciprocidad, actitudes que ayudan a la gente a superar relaciones conflictivas y competitivas para establecer lazos de cooperación y ayuda mutua. Por su parte Baas, referido igualmente por Kliksberg (1999:88) expresa que el capital social tiene que ver con cohesión social e identificación con las formas de gobierno y con expresiones culturales y comportamientos sociales que hacen que la sociedad sea más cohesiva y represente más que una suma de individuos. Considera que los arreglos institucionales horizontales tienen un efecto positivo en la generación de redes de confianza, buen gobierno y equidad social, y que el capital social contribuye de manera importante a estimular la solidaridad y a superar fallas del mercado a través de acciones colectivas y del uso comunitario de recursos.

A la par de las definiciones señaladas, es necesario acotar que el capital social es un concepto situacional y dinámico, que implica una visión más abierta de la acción social y más idónea para acoger las innovaciones a través de la interacción social y el desarrollo de nuevas formas de cooperación. En tal sentido, al hacer transferencia de este concepto a los procesos empresariales o productivos, el mismo es definido por Piselli (2003:55) como un recurso para la acción que hace 


\section{Cuadro 3}

Implicaciones derivadas de la conformación de redes empresariales

\begin{tabular}{|c|c|}
\hline $\begin{array}{c}\text { Actores beneficiados } \\
\text { por la conformación de } \\
\text { redes de empresas turísticas }\end{array}$ & $\begin{array}{l}\text { Implicaciones derivadas de la conformación } \\
\text { de redes de empresas turísticas }\end{array}$ \\
\hline $\begin{array}{l}\text { Organizaciones empresariales } \\
\text { vinculadas con la actividad turística } \\
\text { (empresas de alojamiento, restauración, } \\
\text { intermediación turística, transporte y } \\
\text { actividades complementarias) }\end{array}$ & $\begin{array}{l}\text { - Aprendizaje colectivo e intercambio: transferencia de } \\
\text { conocimientos, intercambio de información productiva y } \\
\text { tecnológica, mejora de procesos operativos y en la ela- } \\
\text { boración de productos y servicios de carácter turístico. } \\
\text { - Especialización en la prestación de servicios turísticos. } \\
\text { - Inversiones empresariales colectivas para la ejecución } \\
\text { de proyectos turísticos. } \\
\text { - Desarrollo de productos/servicios turísticos. } \\
\text { - Impulso para la creación y desarrollo de nuevas empre- } \\
\text { sas y procesos de emprendimiento empresarial. } \\
\text { - Fortalecimiento del sector turístico y sectores conexos. }\end{array}$ \\
\hline Comunidad & $\begin{array}{l}\text { - Desarrollo de valores culturales vinculados a la activi- } \\
\text { dad turística. } \\
\text { - Formación del recurso humano de la localidad. } \\
\text { - Incremento del nivel de vida de la comunidad. } \\
\text { - Generación de nuevas fuentes de trabajo. } \\
\text { - Estímulo para el desarrollo de otros sectores producti- } \\
\text { vos conexos a la actividad turística. } \\
\text { - Fortalecimiento de la identidad local. } \\
\text { - Creación de imagen de marca y posicionamiento del te- } \\
\text { rritorio como destino turístico. }\end{array}$ \\
\hline Turistas & $\begin{array}{l}\text { - Satisfacción de necesidades y expectativas } \\
\text { - Nuevos servicios para los turistas. }\end{array}$ \\
\hline
\end{tabular}

Fuente: Elaboración propia (2012).

posible al sector (individual o colectivo) el logro de ciertos fines que de otro modo (o con costos muy altos) serían inalcanzables.

A lo anterior se adiciona el planteamiento de Vega (2004:49-50) quien considera que las empresas poseen como parte de su estructura el capital social, traducido en el poder, el prestigio, las relaciones con otras organizaciones, los recursos financieros y sociales, entre otros; la base de la conformación de una red empresarial está dada por la similitud de actitudes, comportamientos y de su capital social. Agregando además que una empresa difícilmente se relacionará con otra compartiendo objetivos, funciones, capital, si no poseen elementos en común, como por ejemplo la elaboración de un producto similar o la provisión de un servicio complementario.

Ahora bien, se puede afirmar que el capital social se sustenta en valores que se convierten en normas, como la con- 


\section{Diagrama 1 \\ Redes de empresas turísticas: Actores clave e Implicaciones}

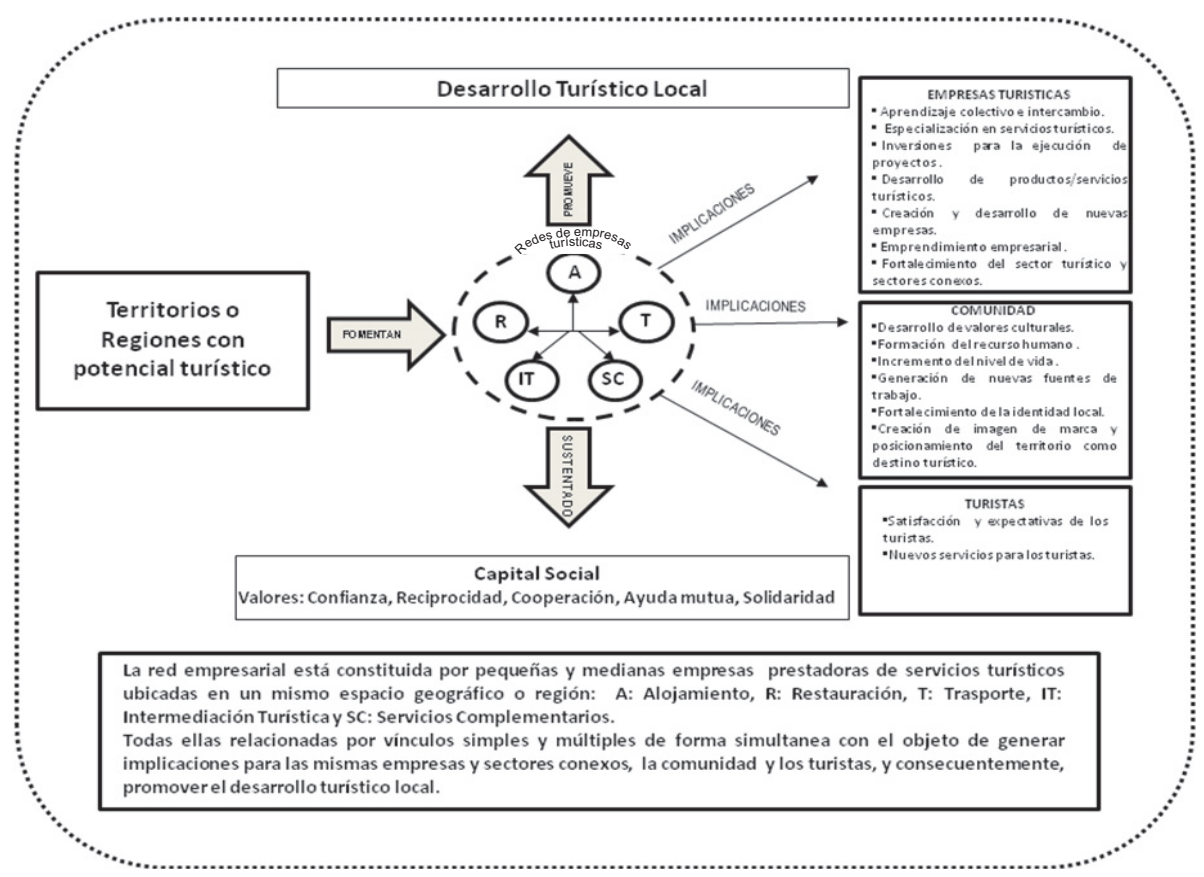

Fuente: Elaboración propia (2012).

fianza, la solidaridad o la reciprocidad. A partir de estas normas se construyen las redes, las organizaciones y las instituciones que permiten la interacción social y el avance de las sociedades, las cuales además generan una serie de efectos que tendrán incidencia de manera determinante en los esfuerzos del desarrollo de las localidades.

A la luz de todo lo anterior se infiere que los principales valores que sustentan la conformación de redes de carácter empresarial y en este caso muy particular las redes de empresas turísticas, serían los siguientes: confianza, reciprocidad, cooperación, ayuda mutua, solidaridad, entre otros.
En el Diagrama 1, se representan los principales valores que sustentan la conformación de redes empresariales y sus implicaciones en el contexto del desarrollo turístico local.

\section{Conclusiones}

Se concluye que las redes de cooperación empresarial en el sector turístico están constituidas por un conjunto de empresas dedicadas a la prestación de servicios de alojamiento, restauración, intermediación turística, trasporte turístico y oferta complementaria que se vinculan entre sí, por relaciones de intercambio e interdependencia, con el objeto de lograr 
ventajas competitivas para ellas y la promoción de procesos de desarrollo para la localidad donde se encuentran establecidas, la cual posee potencialidades turísticas, tales como: recursos naturales, culturales, históricos e infraestructura física.

El fomento de este tipo de estructuras (redes de cooperación empresarial) en las regiones o territorios con recursos y potencialidades turísticas se constituye en una variable estratégica con significativas implicaciones para las propias empresas, la comunidad, los turistas y por consiguiente para el lugar que al final lo que busca es su consolidación como destino turístico, y consecuentemente, su desarrollo económico.

Adicionalmente, resulta importante destacar que la conformación de redes organizacionales debe soportarse en valores tales como: confianza, reciprocidad, cooperación, ayuda mutua, solidaridad; vale decir, en el capital social presente en las empresas locales dedicadas a la actividad turística; situación que favorecerá el logro de objetivos compartidos, estimulando el desarrollo del sector y del entorno territorial.

De igual forma, para alcanzar todo lo antes descrito, se requiere de una actitud proactiva de las instituciones que componen el Estado y de los gobiernos, pues debe existir un poder político-social que sirva como coordinador de las iniciativas de cooperación e integración de los diferentes actores que hacen vida en las regiones o localidades con potencial turístico. Sobre todo, considerando que la actividad turística se sustenta en el uso de los recursos naturales y el espacio como medios de producción, los cuales son considerados, como bienes de uso y dominio público.

\section{Referencias bibliográficas}

Acerenza, Miguel (2007). Desarrollo Sostenible y Gestión del Turismo. Editorial Trillas. México.

Alburquerque, Francisco (1997). Metodología para el desarrollo económico local. ILPES. Chile.

Alburquerque, Francisco (2003). Teoría y Práctica del Enfoque del Desarrollo Local. Unión Europea. Chile.

Andreu, Luisa y Parra, Eduardo (2007). Gestión de Redes en Empresas y Destinos Turísticos. Pasos, Revista de Turismo y Patrimonio Cultural. Vol. $5 \mathrm{~N}^{\circ} 3$. España. Universidad de La Laguna, pp. 399-402.

Artesi, Liliana (2002). Turismo, Desarrollo Local y Redes. Revista Aportes y Trasferencias. Vol. 6 №2. Argentina. Universidad Nacional de la Patagonia Austral, pp. 71-92.

Bonomie, María y Meleán, Rosana (2007). Redes empresariales como estrategia de cooperación en el Sector Avícola del estado Zulia. Revista Compendium. №19. Venezuela. Universidad Centro Occidental Lisandro Alvarado, pp. 5-30.

Calderón, Francisco (2010). ¿Turismo versus Desarrollo? Una perspectiva crítica de las interacciones entre turismo y desarrollo. Revista TURyDES. Vol.3 NN7. Abril (2010). España. Universidad de Málaga.

Fernández, Gladys y Narváez, Mercy (2011). Asociatividad empresarial: estrategia para la competitividad en las pymes del sector turístico. Revista Visión Gerencial. Año 10 No2. Venezuela. Universidad de los Andes, pp. 295-308.

Fernández, Juan C. y Arranz, Nieves (1999). Las Redes de Cooperación Empresarial: ¿Una Organización para el próximo milenio? Revista Dirección y Organización (DyO). № 21. 12-19. Dis- 
ponible: http://www.revistadyo.com/ index.php/dyo/article/view/289/289.

Francés, Antonio (2008). Redes de Cooperación. En: Compromiso Social: gerencia para el siglo $\mathrm{XXI}$. Ediciones IESA. Venezuela.

González, Lydia (2003). Cooperación y Empresas. Retos, Presente y Futuro. Thomson Editores Spain. Madrid.

González, Tania (2007). Redes de cooperación empresarial internacionales vs redes locales. Revista Venezolana de Gerencia. Vol. 12 №37. Venezuela. Universidad del Zulia, pp. 9-26.

Iglesias, David y Ramírez, Javier (2008). La formación de sistemas productivos locales. Revista Teoría y Praxis. Año 4 N5. México. Universidad de Quintana Roo, pp. 51-67.

Kliksberg, Bernardo (1999). Capital social y cultura, claves esenciales del desarrollo. Revista de la CEPAL. N69. Chile. Comisión Económica para América Latina y el Caribe. Diciembre 1999, pp. 85-102.

Lynch, Paul (2000). Networking in the homestay sector. The Services Industries Journal. 20(3). pp, 197-223. Taylor \& Francis Group. ISSN 0264-2069.

Martín, Inmaculada y Gaspar, Ana (2008). La cooperación empresarial como forma de crecimiento: Las nuevas redes de empresas en el sector turístico. Revista TEC Empresarial. Vol.2 Ed.1.Escuela de Administración de Empresas del Instituto Tecnológico de Costa Rica, pp. 35-46.
Mc.Intosh, Robert; Goeldner, Charles; Ritchie, J.R. (2008). Turismo: Planeación, Administración y Perspectivas. Editorial Limusa, S.A. México.

Morrison, Alison; Lynch, Paul; Johns, Nick (2004). International tourism networks. International Journal of Contemporary Hospitality Management. Vol.16 N³, pp. 197-202. Emerald Group Publishing Limited. ISSN 0959-6119.

Parra, Eduardo y Calero, Francisco (2006). Gestión y Dirección de Empresas Turísticas. Mc Graw-Hill/Interamericana de España, S.A.U. España.

Piselli, Fortunata (2003). El Capital Social. Instrucciones de uso. Fondo de Cultura Económica. Argentina.

Varisco, Cristina (2007). Sistema Productivo Turístico y Desarrollo Local. Revista Ciencias Sociales Online. Vol. IV N ${ }^{\circ}$ 2. Chile. Universidad de Viña del Mar, pp. 15-36. Disponible: http://www. uvm.cl/csonline/2007_2/pdf/varisco.pdf.

Vázquez Barquero, Antonio (2000). La Política de Desarrollo Económico Local y Descentralización Fiscal. Editorial Pirámide. Madrid.

Vázquez Barquero, Antonio (2005). Las nuevas fuerzas del desarrollo. Antoni Bosch, editor, S.A. España.

Vega, Marinela (2004). REDES Interacción organizacional inteligente. Editorial de la Universidad del Zulia. Venezuela. 